\title{
Brain iron and neurodegenerative disorders
}

\author{
Farukh Jabeen and Ming $\mathrm{Fu}^{*}$ \\ Cardiovascular and Metabolic Research Unit, Laurentian University, Sudbury, Ontario, Canada
}

Iron in the brain plays a crucial role in maintaining normal physiological functions through its participation in many cellular activities such as mitochondrial respiration, myelin synthesis, and neurotransmitter synthesis and metabolism, however, excess iron is a potent source of oxidative damage, to neuronal cells through free radical formation, [1]. At the end of last century, abnormally high levels of iron in the brain had been reported in a number of neurodegenerative disorders (NDs), including Hallervorden-Spatz syndrome, Parkinson's disease (PD) and Alzheimer's disease (AD) [2-5]. However, it was not known at that time, whether the iron accumulation in the brain was an initial event which leads to neuronal death or it was a consequence of the disease progression. In 2001, Prof. Zhong-Ming Qian [6] in Hong Kong Polytechnic University proposed for the first time that, at least in some neurodegenerative disorders, brain iron misregulation is an initial cause of neuronal death. Two years later, in 2003, Profs. Qian and Ya Ke [7] summarized the evidence that the misregulation in brain iron metabolism is one of the basic causes of neuronal death in some neurodegenerative disorders. Their findings made a great breakthrough in the etiological research of neurodegenerative disorders and also opened a novel avenue for the scientific community to continue studies in this new field.

Today, abnormally increased iron level in the brain has been well-confirmed in various neurodegenerative diseases including neurodegeneration with brain iron accumulation (NBIA). NBIA is a heterogeneous and complex group of inherited neurodegenerative diseases, characterized by excessive iron accumulation in the globus pallidus and other brain regions [8,9]. Clinical features include Parkinsonism and severe dystonia, gait abnormalities, cognitive dysfunction, pyramidal signs, and retinal abnormalities $[8,10]$. So far, mutations in 10 genes have been identified [11] including ferritin light chain (FTL) and ceruloplasmin (CP). Neuroferritinopathy (NFP) and ceruloplasminemia (CPM), induced by mutation in FTL and $\mathrm{CP}$ respectively, have been demonstrated to be directly caused by abnormalities in iron metabolism, mainly in neurons or astrocytes $[8,11]$. Moreover, pantothenase kinase-associated neurodegeneration (PKAN) is the most common form of NBIA (30-50\% cases) which is due to mutation in PANK2 (a pantothenate kinase) gene. The cysteinemediated iron accumulation in the brain, induced by mutation in PANK2, via a free radical pathway, is thought to be a direct cause to leading to neuronal death in this disorder [10,12-15]. The connection between the mutations in other genes of NBIA, including PLA2G6, WDR45, ATP13A2, C19orf12, FA2H, CoASY and C2orf37, and brain iron metabolism is currently unknown. However, these genes are known to be mainly involved in lipid metabolism (CoASY, PLA2G6, FA2H and C19orf12) and autophagy (WDR45 and ATP13A2) $[9,11]$. Recent evidence has shown that autophagy is crucially involved in cellular iron handling and that a number of genes involved in lipid metabolism are required for ferroptosis, an iron-dependent cell death
[16]. These findings suggest those autophagy and lipid metabolisms are both associated with iron metabolism.

In several other neurodegenerative diseases including $\mathrm{AD}, \mathrm{PD}, \mathrm{HD}$, multiple sclerosis, amyotrophic lateral sclerosis and Friedreich's ataxia, iron dyshomeostasis, oxidative stress and mitochondrial injury have been suggested to constitute a common pathway to cell death $[1,17,18]$ although the pathological hallmarks of these neurodegenerative diseases vary. Indeed, many proteins initially characterized in those diseases such as amyloid- $\beta$ protein, $\alpha$-synuclein, and huntingtin have found to be linked with iron neurochemistry $[19,20]$. The presence of 5'UTR sequences in the amyloid precursor protein (APP) and $\alpha$-synuclein transcripts, the activity of APP as a neuronal iron export ferroxidase, $\alpha$-synuclein and prion protein $\left(\mathrm{PrP}^{\mathrm{C}}\right)$ as a ferrireductase, the functional role of $\mathrm{PrP}^{\mathrm{C}}$ in iron transport, the ability of iron to enhance neurotoxicity of amyloid beta $(A \beta)$ and sequestration of iron in $\mathrm{PrP}^{\mathrm{Sc}}$-protein complexes [21-23] leaves little doubt that iron plays a significant role in the neurotoxicity associated with $\mathrm{AD}, \mathrm{PD}$ and HD [19,24,25]. Furthermore, iron chelators have shown their efficacy against neurodegeneration in a series of animal models and been applied in several clinical trials [26]. A novel multimodal brain-permeable iron-chelating compound M30 and HLA20, the were demonstrated to possess neuroprotective/neurorescue activities both in vitro and in vivo against several insults applicable to various neurodegenerative diseases, such as $\mathrm{AD}$ and $\mathrm{PD}$ [27]. Moreover, three smaller clinical trials targeting metal interactions with $A \beta$ have shown benefit for patients $[28,29]$ while several major clinical trials targeting $\mathrm{A} \beta$ by Pfizer, Lilly and Johnson \& Johnson have failed [19,30,31]. All of these therapeutic studies provided neuropharmacological evidence to further support a causative interplay between brain iron misregulation and neuronal death.

The new progresses obtained during the past few years strengthen the belief that the brain iron misregulation is one of the initial causes of neuronal death probably in most if not all of the neurodegenerative disorders. However, in order to completely understand the link between iron and neuronal death in neurodegenerative disorders, further studies on how iron homeostasis is maintained in the brain are still needed in spite of the recent studies have greatly improved our knowledge of this topic. How the expression of iron transport proteins is controlled in the brain under physiological circumstances and what are the genetic and non-genetic causes that might lead to misregulation of brain iron metabolism are another two key questions to be considered /worth exploration/ addressed by researchers in detail to entangle/elaborate clearly the significance of role of iron in

Correspondence to: $\mathrm{Fu} \mathrm{M}$, Cardiovascular and Metabolic Research Unit, Laurentian University, Sudbury, Ontario, Canada, Tel: 1-705-675-1151, E-mail: MFU@LAURENTIAN.CA

Received: August 06, 2017; Accepted: August 21, 2017; Published: August 23, 2017 
neurodegenration. In addition, iron should be considered as a new target for pharmacological intervention in these diseases. Keeping brain iron at optimum level required for normal brain activities, reduction in high level of iron toward normal levels or hampering increases in iron level in the aging brain may be a promising therapeutic strategy in all iron-associated neurodegenerative disorders. Undoubtedly, intensive studies on the development of specific therapeutic approaches will make key contributions to the prevention and treatment of these disorders at large.

\section{References}

1. Belaidi AA, Bush AI (2016) Iron neurochemistry in Alzheimer's disease and Parkinson's disease: targets for therapeutics. J Neurochem 139 Suppl 1: 179-197. [Crossref]

2. Swaiman KF (1991) Hallervorden-Spatz and brain iron metabolism. Arch Neurol 48: 1285-1293. [Crossref]

3. Qian ZM, Wang Q (1998) Expression of irontransport proteins and excessive iron accumulation of iron in the brain in neurodegenerative disorders. Brain Res Rev 27: 257-267. [Crossref]

4. Aisen P, Wessling-Resnick M, Leibold E (1999) Iron metabolism. Curr Opin Chem Biol 3: 200-206. [Crossref]

5. Jellinger KA (1999) The role of iron in neurodegeneration. Drugs Aging 14: 115-140. [Crossref]

6. Qian ZM, Shen X (2001) Brain iron transport and neurodegeneration. Trends Mol Med 7: 103-108. [Crossref]

7. Ke Y, Ming Qian Z (2003) Iron misregulation in the brain: a primary cause of neurodegenerative disorders. Lancet Neurol 2: 246-253. [Crossref]

8. Rouault TA (2013) Iron metabolism in the CNS: implications for neurodegenerative diseases. Nat Rev Neurosci 14: 551-564. [Crossref]

9. Meyer E, Kurian MA, Hayflick SJ (2015) Neurodegeneration with Brain Iron Accumulation: Genetic Diversity and Pathophysiological Mechanisms. Annu Rev Genomics Hum Genet 16: 257-279. [Crossref]

10. Zhou B, Westaway SK, Levinson B, Johnson MA, Gitschier J, et al. (2001) A novel pantothenate kinase gene (PANK2) is defective in Hallervorden-Spatzsyndrome. Nat Genet 28: 345-349. [Crossref]

11. Arber CE, Li A, Houlden H, Wray S (2016) Review: Insights into molecular mechanisms of disease in neurodegeneration with brain iron accumulation: unifying theories. Neuropathol Appl Neurobiol 42: 220-241. [Crossref]

12. Rouault TA (2001) Iron on the brain. Nat Genet 28: 299-300. [Crossref]

13. Hayflick SJ, Westaway SK, Levinson B, Zhou B, Johnson MA, et al. (2003) Genetic, clinical, and radiographic delineation of Hallervorden-Spatz syndrome. $N$ Engl J Med 348: 33-40. [Crossref]

14. Hayflick SJ (2006) Neurodegeneration with brain iron accumulation: from genes to pathogenesis. Semin Pediatr Neurol 13: 182-185. [Crossref]
15. Sebastiani G, Pantopoulos K (2011) Disorders associated with systemic or local iron overload: from pathophysiology to clinical practice. Metallomics 3: 971-986. [Crossref]

16. Dixon SJ, Lemberg KM, Lamprecht MR, Skouta R, Zaitsev EM, Gleason CE, et al (2012) Ferroptosis: an iron-dependent form of nonapoptotic cell death. Cell 149: 10601072. [Crossref]

17. Stephenson E, Nathoo N, Mahjoub Y, Dunn JF, Yong VW (2014) Iron in multiple sclerosis: roles in neurodegeneration and repair. Nat Rev Neurol 10: 459-468. [Crossref]

18. Peters DG, Connor JR, Meadowcroft MD (2015) The relationship between iron dyshomeostasis and amyloidogenesis in Alzheimer's disease: Two sides of the same coin. Neurobiol Dis 81: 49-65. [Crossref]

19. Ayton S, Lei P, Bush AI (2013) Metallostasis in Alzheimer's disease. Free Radic Biol Med 62: 76-89. [Crossref]

20. Hare DJ, Arora M, Jenkins NL, Finkelstein DI, Doble PA, et al. (2015) Is early-life iron exposure critical in neurodegeneration? Nat Rev Neurol 11: 536-544. [Crossref]

21. Duce JA, Tsatsanis A, Cater MA, James SA, Robb E, et al. (2010) Iron-export ferroxidase activity of $\beta$-amyloid precursor protein is inhibited by zinc in Alzheimer's disease. Cell 142: 857-867. [Crossref]

22. Lei P, Ayton S, Finkelstein DI, Spoerri L, Ciccotosto GD, et al. (2012) Tau deficiency induces parkinsonism with dementia by impairing APP-mediated iron export. Nat Med 18: 291-295. [Crossref]

23. Bush AI (2013) The metal theory of Alzheimer's disease. J Alzheimers Dis 33: S27781. [Crossref]

24. Singh N, Haldar S, Tripathi AK, Horback K, Wong J, et al. (2014) Brain iron homeostasis: from molecular mechanisms to clinical significance and therapeutic opportunities. Antioxid Redox Signal 20: 1324-1363. [Crossref]

25. Carboni E, Lingor P (2015) Insights on the interaction of alpha-synuclein and metals in the pathophysiology of Parkinson's disease. Metallomics 7: 395-404. [Crossref]

26. Dusek P, Schneider SA, Aaseth J (2016) Iron chelation in the treatment of neurodegenerative diseases. J Trace Elem Med Biol 38: 81-92. [Crossref]

27. Weinreb O, Amit T, Mandel S, Youdim MB (2012) Novel therapeutic approach fo neurodegenerative pathologies: multitarget iron-chelating drugs regulating hypoxiainducible factor 1 signal transduction pathway. Neurodegener Dis 10: 112-115. [Crossref]

28. Lannfelt L, Blennow K, Zetterberg H, Batsman S, Ames D, et al. (2008) PBT2-201EURO study group. Safety, efficacy, and biomarker findings of PBT2 in targeting Abeta as a modifying therapy for Alzheimer's disease: a phase IIa, double-blind, randomised, placebo-controlled trial. Lancet Neurol 7: 779-786. [Crossref]

29. Faux NG1, Ritchie CW, Gunn A, Rembach A, Tsatsanis A, et al. (2010) PBT2 rapidly improves cognition in Alzheimer's Disease: additional phase II analyses. J Alzheimers Dis 20: 509-516. [Crossref]

30. Karran E, Mercken M, De Strooper B (2011) The amyloid cascade hypothesis for Alzheimer's disease: an appraisal for the development of therapeutics. Nat Rev Drug Discov 10: 698-712. [Crossref]

31. Callaway E (2012) Alzheimer's drugs take a new tack. Nature 489: 13-14. [Crossref]

Copyright: $@ 2017 \mathrm{Fu}$ M, Jabeen F. This is an open-access article distributed under the terms of the Creative Commons Attribution License, which permits unrestricted use, distribution, and reproduction in any medium, provided the original author and source are credited. 